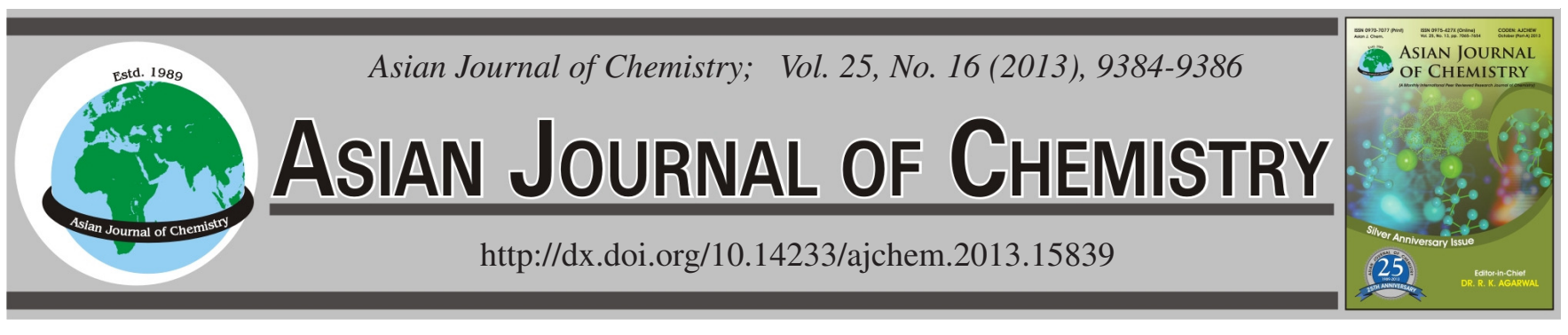

\title{
Energy Dispersive X-ray Fluorescence Analysis of Pre and Post-1850 Historical Documents Obtained from the National Library of South Africa
}

\author{
K. Dzinavatonga ${ }^{1, *}$, T.R. Medupe ${ }^{1}$, L.C. Prinsloo ${ }^{2}$ and Eno E. Ebenso ${ }^{3}$
}

\begin{abstract}
${ }^{1}$ Department of Physics and Electronics, North-West University (Mafikeng Campus), Private Bag X2046, Mmabatho, South Africa ${ }^{2}$ Department of Physics, University of Pretoria, Pretoria, South Africa

${ }^{3}$ Material Science Innovation \& Modelling (MaSIM) Research Focus Area, Faculty of Agriculture, Science and Technology, North-West University (Mafikeng Campus), Private Bag X2046, Mmabatho 2735, South Africa
\end{abstract}

*Corresponding author: E-mail: kaitano.dzinavatonga@nwu.ac.za

\begin{abstract}
Energy dispersive X-ray fluorescence technique was used to study the elemental composition of some historical paper samples obtained from the National Library of South Africa. Six elements namely $\mathrm{Fe}, \mathrm{Cu}, \mathrm{Mn}, \mathrm{Ca}, \mathrm{K}$ and $\mathrm{S}$ were detected. It was found that older documents had higher concentrations of $\mathrm{Ca}$ and hence a considerable alkaline buffer than recent documents. It was also observed that the levels of $\mathrm{Ca}$ dropped significantly between 1800 and 1890 coinciding with the period paper making technology also changed. The concentrations of $\mathrm{K}$ and $\mathrm{S}$ also decreased around 1890. Iron remained fairly high and was detected in all the samples. Copper and manganese were found to be at very low concentrations compared to Fe. This research shows that Fe has the potential to impact negatively on paper permanency unless de-acidification is undertaken because of its relative abundance compared to $\mathrm{Cu}$.
\end{abstract}

Key Words: EDXRF, Historical documents, Elemental composition, Oxidative degradation.

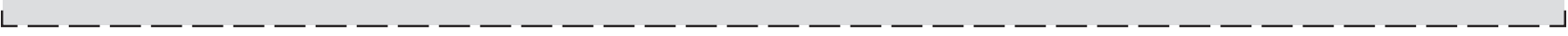

\section{INTRODUCTION}

Historical documents of intrinsic value are often destroyed by a variety of paper/cellulose degradation agents. These range from the environmental conditions to the constituent material that makes up such documents. The rate at which the historical documents degrade with time depend on the sizing material used, fillers, included transition metals as well as the cellulose fibre morphology and its accessibility. The processes by which historical documents degrade with time are well documented ${ }^{1-4}$. The degradation mechanisms as well as potential intervention techniques have been well studied ${ }^{3}$. The degradation process often produce specific byproducts notably carbonyl and carboxyl functional groups that can give an indication of the underlying chemical process.

An analysis of the history of paper production shows that there was a marked change in the paper making process around 1850 AD. This was mainly due to the shift from potassium aluminum sulphate (alum) to aluminium sulphate as a sizing agent ${ }^{5}$. It has been observed that such a change in sizing agent was associated with increasing acidity of the paper produced ${ }^{6}$. Transition metals like iron, copper and manganese play a significant role in influencing the oxidative degradation of cellulose through their catalytic action. The presence of such transition metal ion species, though in trace quantities, is potentially detrimental to the oxidative stability of paper. It therefore means the detection of these ion species in historical documents is of importance from a document conservation point of view.

Metal ions can be hydrolyzed and displace hydrogen during reaction with water as follows:

$$
\mathrm{M}^{\mathrm{z+}}+\mathrm{zH}_{2} \mathrm{O} \longrightarrow \mathrm{M}(\mathrm{OH})_{\mathrm{z}}+\mathrm{zH}^{+}
$$

The hydrogen ions can then induce hydrolysis and cross linking reactions in secondary reactions. The metal hydroxides can also be transformed to oxides with further hydrogen ion formation ${ }^{4}$. This means that metal oxides and metal hydroxides can catalyze cellulose hydrolysis in the absence of oxygen. The degradation of cellulose is more pronounced the easily hydrolyzed the metal ${ }^{6}$ in the order $\mathrm{Fe}^{3+}, \mathrm{Fe}^{2+}, \mathrm{Cu}^{2+}$ and $\mathrm{Mn}^{2+}$. Hydrolytic degradation is more dominant in an acidic paper than in alkaline paper.

Acids in paper can be neutralized by using aqueous solutions of calcium or magnesium hydrogen carbonates ${ }^{3}$ through the so called Bookmaker's process. This process effectively raises the $\mathrm{pH}$ range of paper to between 7 and 9, transforming it to archival quality. It has, however, been observed that the catalytic activity of copper increases steadily 
in the $\mathrm{pH}$ interval of $7-9^{4}$. It is therefore plausible to conclude that the higher $\mathrm{pH}$ macromolecular environment may decrease the activity of Fe-containing paper samples but not in paper samples containing $\mathrm{Cu}$. Copper therefore remains a threat to paper stability even after de-acidification process. It is therefore important that the elemental content of archival material be ascertained in order to prepare for a comprehensive preservation intervention. The purpose of this research is to determine whether the change in the sizing material used in paper production can be associated with the change in the elemental content of the paper produced, particularly the concentrations of transition metals.

\section{EXPERIMENTAL}

A comparison of the elemental composition of pre- and post- 1850 historical documents obtained from the National Library of South Africa (NLSA) is hereby presented using $\mathrm{XRF}$ analytical technique. XRF spectrometry is a well established technique for elemental analysis at micro and trace levels. This method provides a quick non-destructive analysis and has sensitivities at the level of parts per million ${ }^{7}$. It gives information about the elemental composition without the need for any pretreatment. The technique is independent of the chemical state of the element but it does not give information about the chemical bonds of the detected elements.

Sampling was permitted because NLSA wished to assess its collection for potential of degradation. This sampling was done only for those items that the library possessed more than one copy. The NLSA also runs regulatory deposits for all newspapers. This means that they need to continuously monitor their collection for preservative purposes to ensure they extend the life span of books, newspapers, periodicals and government gazettes that are under their care. The materials sampled in this study therefore included most of the items named above. The items sampled are dated from 1732 to 1925 . This time span allows for comparison of papers produced before and after $1850 \mathrm{AD}$ when paper making technology changed. The samples collected are shown in Table-1.

Paper samples of size $0.25-1 \mathrm{~cm}^{2}$ were cut from the lower bottom corners of the selected documents. Metal concentrations in the paper samples were measured using an EDX-720 X-ray fluorescence spectrometer. The surface of the sample is irradiated by an X-ray beam. When an appropriate energy is applied, a photoelectron is emitted. The vacancy left by the ejection of a photoelectron is filled by an outer electron while the energy difference is emitted in the form of X-ray fluorescence radiation. The excitation energies correspond to the emission lines of the elements while the intensity of the emission provide information about their concentration on the sample surface ${ }^{8}$. The spectra were recorded in air and the instrument energy range was automatically set at 0 to $40 \mathrm{keV}$.

\section{RESULTS AND DISCUSSION}

The concentrations of different elements found in the paper samples studied are shown in Fig. 1.

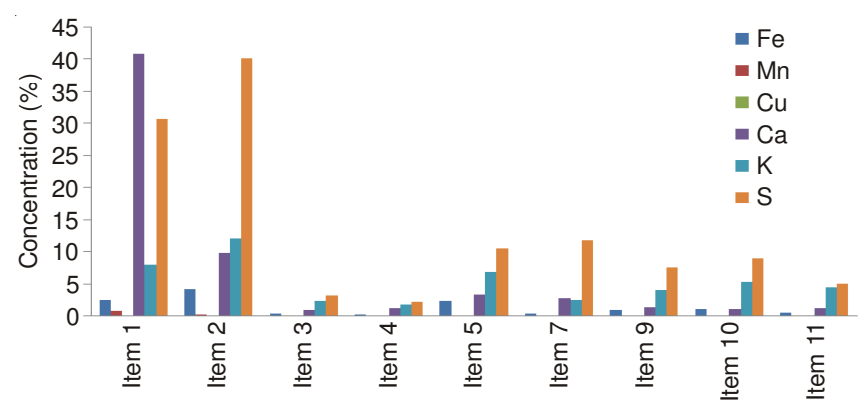

Fig. 1. Elemental composition of paper samples (for items please refer Table-1)

The key transition metals of interest are $\mathrm{Fe}, \mathrm{Cu}$ and $\mathrm{Mn}$ while elements $\mathrm{Ca}, \mathrm{K}$ and $\mathrm{S}$ give an indication of the macromolecular environment of the transition metals in the paper samples. Because of the large difference in concentrations between the transition metals and the macromolecular environment elements, it is convenient to plot these elements on different graphs with different scales.

In order to understand how effective the transition metals will be as oxidative agents, it was imperative that we have a clear picture of their environment within the paper sample. All the samples studied have calcium, with the highest concentration of $41 \%$ in the oldest sample of 1732 is calcium (Fig. 2). It should also be noted that this sample is still in very good physical condition.

There is a greater concentration of $\mathrm{Ca}$ in older papers than in the recent paper samples. Calcium is associated with alkaline carbonates such as $\mathrm{CaCO}_{3}$ which is generally regarded as beneficial to paper stability. High $\mathrm{Ca}$ concentration means that the paper sample has a large alkaline buffer and is of good archival quality ${ }^{6}$. This would also mean that the effectiveness of $\mathrm{Fe}$ as an oxidative catalyst is greatly reduced ${ }^{9}$. There is a notable drop in the concentration of Ca between 1803 and

TABLE-1

COLLECTION OF SAMPLES STUDIED

\begin{tabular}{clcc}
\hline \multicolumn{1}{c}{ Title } & Classification & Publication date \\
\hline Item & \multicolumn{1}{c}{ Book } & 1732 \\
2 & Het Leven en Bedryf van Michiel De Ruiter. & Book & 1803 \\
3 & South Africa (Barrow) & Book & 1893 \\
4 & The 19 $9^{\text {th }}$ Century (Volume 33) & Newspaper & 1893 \\
5 & The Press & Book & 1896 \\
6 & The 19 $9^{\text {th }}$ Century (Volume 39) & Newspaper & 1897 \\
7 & The Weekly Press & Periodical & 1897 \\
8 & Regulatien : Staatsbiblioteek & Newspaper & 1899 \\
9 & The Weekly Press & Periodical & 1901 \\
10 & Natal Almanac \& Directory & Periodical & 1918 \\
11 & Die Huisgenoot & Newspaper & 1925 \\
\hline
\end{tabular}




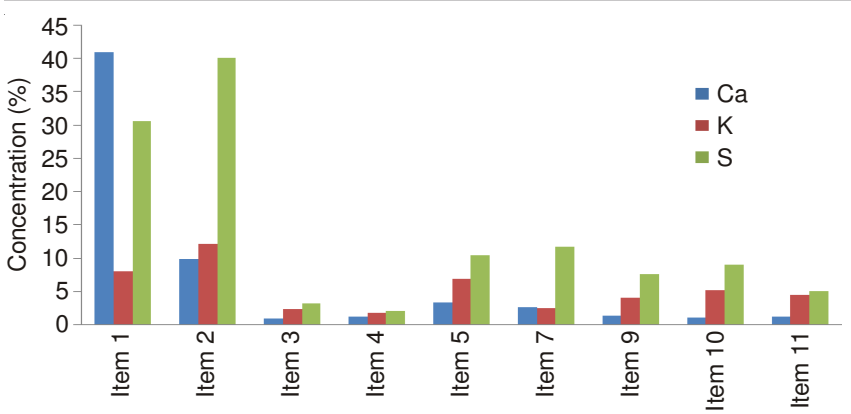

Fig. 2. Concentrations of $\mathrm{Ca}, \mathrm{K}$ and $\mathrm{S}$ in paper samples (for items please refer Table-1)

1893 in the samples studied. This period coincide with the time paper making technology changed from external sizing to internal sizing. Sulphur and potassium are the primary elements of alum. The concentration of alum in the samples studied is therefore inferred from the concentration of $\mathrm{S}$ and $\mathrm{K}$. It can be observed from Fig. 2 that as the concentration of $\mathrm{K}$ decreased so did the concentration of $\mathrm{S}$ and that the concentration of $\mathrm{S}$ was always greater than that of $\mathrm{K}$. The presence of alum also shows that gelatin was used for sizing in the paper samples. Gelatin has been known to play a protective role to cellulose through preferential hydrolysis of protein molecules over those of cellulose ${ }^{10}$. Gelatin can also bind transition metals such $\mathrm{Cu}$ and $\mathrm{Fe}$, thus inhibiting their catalytic role in oxidative degradation of cellulose ${ }^{11}$.

The concentrations of transition metals in the samples studied are shown in Fig. 3. It can also be observed that Fe is present in every sample and that very few samples had $\mathrm{Cu}$ and $\mathrm{Mn}$. This therefore means that iron plays an important role in the chemistry of paper.

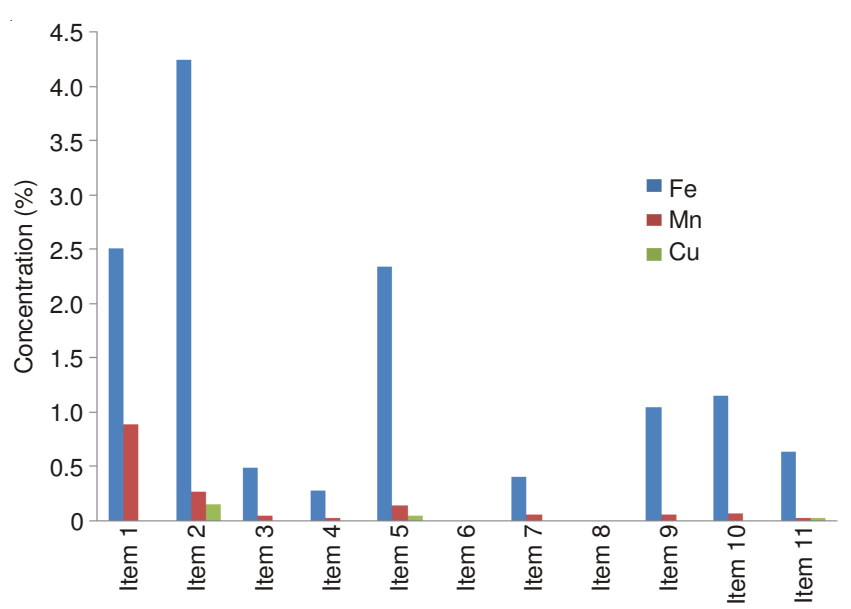

Fig. 3. Transition metal concentrations of the paper samples (for items please refer Table-1)

Iron and copper have been associated with paper foxing ${ }^{12}$ besides their catalytic role in oxidative degradation of paper. An alkaline macromolecular environment has been observed to inhibit the catalytic action of $\mathrm{Fe}$ but not of $\mathrm{Cu}^{13}$. Manganese was found in much lesser conentrations than $\mathrm{Fe}$ and tended to be much less for the more recent documents.

\section{Conclusion}

The concentrations of $\mathrm{Fe}, \mathrm{Cu}, \mathrm{Mn}, \mathrm{Ca}, \mathrm{K}$ and $\mathrm{S}$ were determined using XRF spectra. This study gives us an insight into the distribution of transition metals in paper samples for period under study. Iron was found to be present in all samples while $\mathrm{Cu}$ was found in less than a fifth of the samples. The concentration of Fe remained considerably high through out the period under consideration. These results emphasize the importance of $\mathrm{Fe}$ in paper degradation and that conservation efforts should aim to slow down/arrest the the adverse effects of Fe. The catalytic effect of Fe can be inhibited in an alkaline environment. This means that mass de-acidification undertaken by some libraries and archives can effectively extend the shelf lives of their collections. The presence of $\mathrm{Ca}$ also ensures that there is a sufficient alkaline buffer so that the paper remains of archival quality. The drop in the concentration of Ca starting from around the period 1890 coincide with the time paper making technology changed. That was the period most of the the acidic paper started to be produced. Since the concentrations of Fe remained fairly high even after the notable decrease in $\mathrm{Ca}$ concentration, it means that $\mathrm{Fe}$ was now in an acidic macromolecular environment and its catalytic effect became more pronounced. The catalytic activity of $\mathrm{Cu}$ increases steadily in the $\mathrm{pH}$ range 7-9. A serious implication of this behaviour of $\mathrm{Cu}$ is that oxidative degradation of paper will persist even after deacidification. $\mathrm{K}$ and $\mathrm{S}$ are the characteristic indicators for the presence of alum. Alum can also bind transition metals, therefore it is beneficial to paper permanence as long as the paper remains alkaline. It has been observed that the effectiveness of transition metals as oxidative agents depend on their oxidation states. The determination of these oxidation state in paper samples is the next logical step in order to fully understand the paper degradation chemistry.

By determining the elemental composition and concentration of paper and linking it to the history of paper production, one can determine the origin of the paper as well as estimate its age. Very little research has been done that connects elemental composition and concentrations to hisorical periods. Elemental analysis of paper together with knowledge of the elemental composion of the ink used in a historical document ${ }^{14}$ can thus be used in dating and authenticating such documents.

\section{REFERENCES}

1. J. Lojewska, P. Miøkowiec, T. Lojewski and L.M., Polym. Degrad. Stab., 88, 512 (2005)

2. M. Ali,A.M. Emsley, H. Herman and R.J. Heywood, Polymer, 42, 2893 (2001).

3. M. Polovka, J. Polovkovà, K. Vizàrovà, S. Kirscnerovà, L. Bielikovà and M. Vrskà, Vib. Spectrosc., 41, 112 (2006).

4. V.S. Šelih, M. Strliè, J. Kolar and B. Pihlar, Polym. Degrad. Stab., 92 , 1476 (2007).

5. T. Trafela, M. Strlic, J. Kolar, D.A. Lichtblau, M. Anders, D.P. Mencigar and B. Pihlar, Anal. Chem., 79, 6319 (2007).

6. M. Manso and M.L. Carvalho, Spectrochim. Acta A, 64, 482 (2009).

7. S. Pessana, M. Manso and M.L. Carvahlo, Spectrochim. Acta B, 71-72, 54 (2012).

8. A. Racz, K. Heberger, R. Rajko and J. Elek, Heritage Sci., 1:2 (2013).

9. C.J. Shahani, F.H. Hengemihle, Adv. Chem. Series, 212, 387 (1984).

10. J. Kolar, M. Strlic, M. Budnar, J. Malesic, V.S. Selih and J. Simcic, Acta Chim. Slov., 50, 763 (2003).

11. G. Kolbe, Restaurator, 25, 26 (2004)

12. M. Bicchieri, S. Ronchoni, F.P. Romano, L. Pappalardo, M. Corsi, G. Cristoforetti, S. Legnaioli, V. Palleschi, A. Salvetti and E. Tognoni, Spectrochim. Acta B, 57, 1235 (2002)

13. M. Strlic, J. Kolar, V.S. Selih, D. Kocar and B. Pihlar, Acta Chim. Slov, 50, 619 (2003).

14. K. Nesmerak and I. Nemcova, Anal. Lett., 45, 330 (2012). 